\title{
Rare Case of Rectal Pocket with Ano-Rectal Stenosis in a Post-Operative Case of Stapled Haemorrhoidopexy Treated by Achalasia Balloon Dilatation
}

\author{
Darshan Parekh ${ }^{1}$, Mohan A. Joshi², Samir Rambhia ${ }^{3}$, Vishwajeet Pawar ${ }^{4}$, Anoop Joshi ${ }^{5}$
}

\begin{abstract}
${ }^{1}$ Senior Registrar, Department of General Surgery, LTMMC and LTMGH, Sion, Mumbai, Maharashtra, India. ${ }^{2}$ HOD, Department of General Surgery, LTMMC and LTMGH, Sion, Mumbai, Maharashtra, India. ${ }^{3}$ Assistant Professor, Department of General Surgery, LTMMC and LTMGH, Sion, Mumbai, Maharashtra, India. ${ }^{4}$ Assistant Professor, Department of General Surgery, LTMMC and LTMGH, Sion, Mumbai, Maharashtra, India. ${ }^{5}$ Registrar, Department of General Surgery, LTMMC and LTMGH, Sion, Mumbai, Maharashtra, India.
\end{abstract}

\section{INTRODUCTION}

Stapled haemorrhoidopexy is a convenient and safe modality with good results, but may be followed by unusual and severe postoperative complications. Formation of a rectal pocket and anorectal stenosis are rare but distressing complications. We report a case of rectal pocket formation with anorectal stenosis in a post-operative case of $\mathrm{SH}$, and its management.

\section{PRESENTATION OF CASE}

A 48-year-old male patient underwent SH with $35 \mathrm{~mm}$ stapler, for grade III haemorrhoids. Procedure was uneventful and there were no immediate or early complications. Two months later, he presented with severe pain during defecation and difficulty in passing stools, which persisted in spite of taking stool softeners. On $\mathrm{PR}$, stenosis of staple line could be felt. We did a rectosigmoidoscopy for him and noticed a rectal pouch formation just below the stapler line with ano- rectal stenosis at the staple line (Figure 1). We did a balloon dilatation with a $40 \mathrm{~mm}$ diameter achalasia balloon (Figure 2), of the staple line under fluoroscopy guidance (Figure 3). There were no complications, and post procedure, there was adequate dilatation and obliteration of rectal pouch. Patient was relieved of his complaints.

The incidence of rectal pocket post stapled haemorrhoidopexy ( $\mathrm{SH}$ ) is $2.5 \%^{1}$, and anorectal stenosis is $3-3.5 \%^{2,3}$. We present a rare case of both the complications together causing difficulty in passing stools and pain at defecation in a patient after two months of undergoing stapled haemorrhoidopexy. The complications were discovered on rectosigmoidoscopy. Patient underwent Rigiflex ${ }^{\mathrm{TM}}$ achalasia balloon (Diameter $40 \mathrm{~mm}$ ) dilatation and he was relieved of the stenosis and his symptoms.

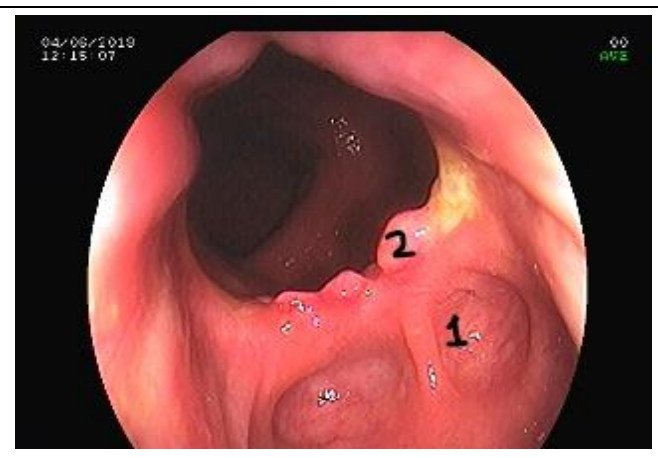

Figure 1.

Colonoscopic Image

1: Rectal Pocket

2: Anorectal Stenosis
Corresponding Author: Dr. Darshan Parekh, \#11, Utsav, Podar Road, Santacruz West, Mumbai-400054, Maharashtra, India.

E-mail: dparekh2108@gmail.com

DOI: 10.14260/jemds/2019/623

Financial or Other Competing Interests: None.

How to Cite This Article:

Parekh D, Joshi MA, Rambhia S, et al. Rare case of rectal pocket with ano-rectal stenosis in a post-operative case of stapled haemorrhoidopexy treated by achalasia balloon dilatation. Evolution Med. Dent. Sci. 2019;8(37):2870-2872, 10.14260/jemds/2019/623

Submission 24-07-2019, Peer Review 01-09-2019, Acceptance 08-09-2019, Published 16-09-2019. 


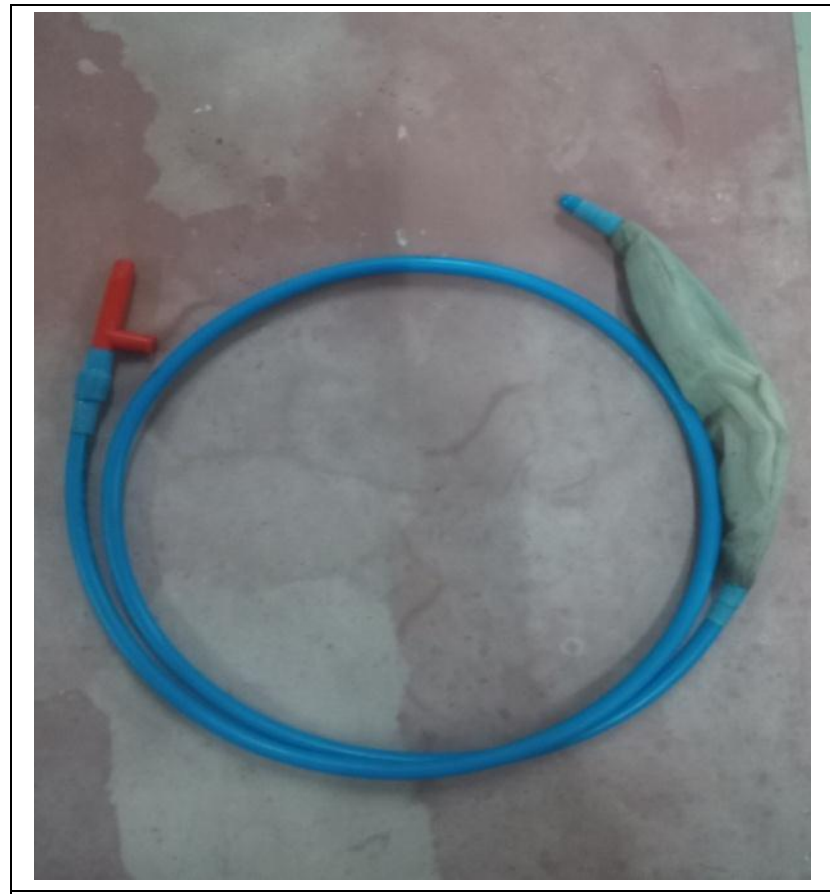

Figure 2. Rigiflex ${ }^{T M}$ Achalasia Balloon

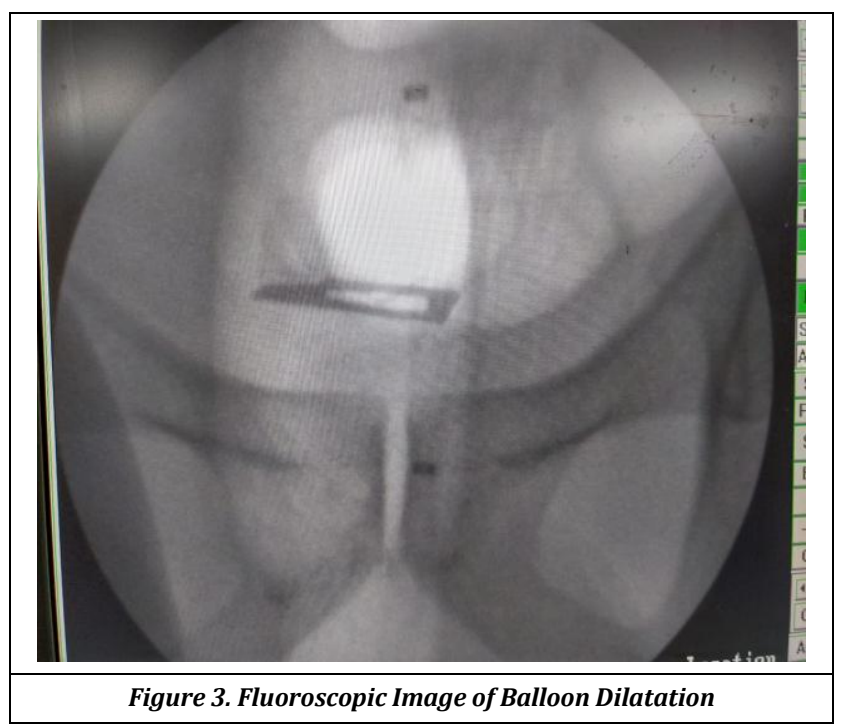

\section{DISCUSSION}

Haemorrhoids are common and $>1$ million individuals are affected by symptomatic haemorrhoids in the western world per year. 4 The most definitive treatment is excisional haemorrhoidectomy (EH) but it is associated with marked post-operative pain. Hence, surgeons were required to innovate alternative treatment options. Stapled haemorrhoidopexy was a landmark change in the treatment of haemorrhoids. This method was established in 1997 by Sir Antonio Longo. ${ }^{5}$ A modified circular stapler is inserted through the anus, and a circular ring of mucosal tissue from the anal canal is excised, well above the dentate line. The redundant, prolapsing mucosa is lifted back into the anal canal by a stapled anastomosis.

One multicenter study has reported that $36.4 \%$ of patients had at least one adverse event following SH. ${ }^{6}$ A systematic review has revealed that $20.2 \%$ had postoperative complications. ${ }^{7}$ In another study in which PPH was done as a day case procedure, $12.7 \%$ of patients required readmission on the day of surgery, mostly due to bleeding, pain and urinary retention. $^{8}$ It has been reported that manual haemorrhoidectomy has equal complications such as bleeding, strictures and fissures. ${ }^{9}$ Although unusual complications (e.g. rectal obliteration, ${ }^{10}$ rectal perforation ${ }^{11,12}$ with retropneumoperitoneum ${ }^{12}$ and pneumomediastinum ${ }^{12,13}$ as well as chronic pain ${ }^{14}$ ) have been reported as well following $\mathrm{SH}$.

A pathological pocket in the lower rectum, resembling a diverticulum or an intramural fistula may be caused by a partial slippage of the purse string. This may lead to an intermittent collection of faecolith followed by inflammation and local sepsis similar to a perirectal or perianal abscess. This would require a lay-open of the pocket which is effective in most of the cases. The incidence of this complication is $2.5 \%{ }^{1}$

Anorectal stenosis is also uncommon. Its incidence has been reported as $3 \%$ and $3.6 \%$ of the operated cases in two series. $^{2,3}$ In another series, it was rare $(1.2 \%)$ and mostly related to a breakdown of the anastomosis. ${ }^{15}$ It has been successfully managed with dilation.

There is no reported case in literature of these two complications existing together. Both complications were managed by a single endoscopic intervention of achalasia balloon dilatation without any need for resurgery. It is a simple, safe, effective and cheap innovative intervention for such a complication of $\mathrm{SH}$.

\section{CONCLUSIONS}

SH is a widely used surgery for the management of haemorrhoids. As prevention is better than cure, the risk of adverse events may be reduced by accurate technique and meticulous selection of patients. If complications occur, they may be managed surgically and non-surgically. We reported two rare complications coexisting and their successful management with the innovative use of an achalasia balloon, without any need of hospitalization.

\section{REFERENCES}

[1] Pescatori M, Spyrou M, Cobellis L, et al. Rectal pocket syndrome after stapled mucosectomy. Colorectal Dis 2006;8(9):808-11.

[2] Pechlivanides G, Tsiaoussis J, Athanasakis E, et al. Stapled transanal rectal resection (STARR) to reverse the anatomic disorders of pelvic floor dyssynergia. World J Surg 2007;31(6):1329-35.

[3] Ellis CN. Stapled transanal rectal resection (STARR) for rectocele. J Gastrointest Surg 2007;11(2):153-4.

[4] Gearhart SL. Diverticular disease and common anorectal disorders. In: Longo, Fauci, Kasper, et al. eds. Harrison's Principles of Internal Medicine. 18 ${ }^{\text {th }}$ edn. McGraw Hill Publication 2012: p. 2502-10.

[5] Longo A. Treatment of haemorrhoids disease by reduction of mucosa and haemorrhoidal prolapse with a circular-suturing device: a new procedure. In: Proceedings of the Sixth World Congress of Endoscopic Surgery, Rome, Italy 1998: p. 777. 
[6] Senagore AJ, Singer M, Abcarian H. A prospective, randomized, controlled multicenter trial comparing stapled haemorrhoidopexy and Ferguson haemorrhoidopexy: perioperative and one-year results. Dis Colon Rectum 2004;47:1824-36.

[7] Tjandra JJ, Chan MK. Systematic review on the procedure for prolapse and haemorrhoids (stapled haemorrhoidopexy). Dis Colon Rectum 2007;50(6):878-92.

[8] Beattie GC, McAdam TK, McIntosh SA, et al. Day case stapled haemorrhoidopexy for prolapsing haemorrhoids. Colorectal Dis 2006;8(1):56-61.

[9] Ravo B, Amato A, Bianco V, et al. Complications after stapled haemorrhoidectomy: can they be prevented? Tech Coloproctol 2002;6(2):83-8.

[10] Cipriani S, Pescatori M. Acute rectal obstruction after PPH stapled haemorrhoidectomy. Colorectal Dis 2002;4(5):367-70.

[11] Wong LY, Jiang JK, Chang SC, et al. Rectal perforation: a life-threatening complication of stapled haemorrhoidectomy: report of a case. Dis Colon Rectum 2003;46(1):116-7.
[12] Ripetti V, Caricato M, Arullani A. Rectal perforation, retropneumoperitoneum and pneumomediastinum after stapling procedure for prolapsed haemorrhoids: report of a case and subsequent consideration. Dis Colon Rectum 2002;45(2):268-70.

[13] Filingieri V, Gravante G. The last images. Pneumoretroperitoneum, pneumomediastinum and subcutaneous emphysema of the neck after stapled haemorrhoidopexy. Tech Coloproctol 2005;9(1):86.

[14] Thaha MA, Irvine LA, Steele RJ, et al. Postdefaecation pain syndrome after circular stapled anopexy is abolished by oral nifedipine. Br J Surg 2005;92(2):20810.

[15] Stuto A, Schwander O, Jayne D. Assessing safety of the STARR procedure for ODS: preliminary results of the European STARR Registry. Dis Colon Rectum 2007;50:724 (abstract). 